\title{
The effects of fit and novelty according to brand collaboration on product attitude: the moderating effect of age
}

\author{
Yu-Kyung Yim, Business Administration, Kumoh National Institute of Technology, Gyeongsangbuk-do, 39177, \\ South Korea. \\ *Gwi-Gon Kim, Business Administration, Kumoh National Institute of Technology, Gyeongsangbuk- \\ do, 39177, South Korea, metheuskim@daum.net \\ *Corresponding Author
}

\begin{abstract}
This study sought to identify two paths (novelty, fit) of the impact of brand collaboration type on product attitude and the moderating effect of age between novelty and attitude. To test this research, four types of questionnaires were used with scenarios and real brands. This research suggests two paths from brand collaboration type (similar vs. non-similar) to product attitude. One is perceived novelty and the other is perceived fit. Second, we tested the effect of perceived novelty $\cdot$ fit on product attitude. Finally, we examined the moderating effect of age. We used 250 of 268 copies for final analysis. This study found that the degree of perceived novelty and fit depending on the type of brand collaboration influenced positively on the product attitude. We also confirmed age moderated the relationship between novelty and attitude. The results of the study are as follows: 1) Perceived novelty by brand collaboration type was higher in collaboration between non-similar categories than similar ones. 2) Perceived fit was higher in collaboration between similar categories than non-similar ones. 3) Perceived novelty has positive effects on product attitude. 4) Perceived fit has positive effects on product attitude. 5) The relationship between perceived novelty and product attitude was moderated by age. In other words, the effect of perceived novelty in collaboration between non-similar categories on product attitude was found to be greater when age is low. Based on the results of this study, the marketers should consider collaborative marketing that gives them a unique and novelty feeling tailored to the characteristics of the new main consumers like the Millennials and Generation Z. This study was based on data collected through responses from residents of Republic of Korea. In the future, conducting research on a countryby-country basis will help overseas marketing strategies.
\end{abstract}

Keywords: Brand Collaboration, Perceived Fit, Perceived Novelty, Millennials, Generation Z Received: 03.12.2020 Accepted: 14.01.2021 $\quad$ Published: 03.02.2021

\section{INTRODUCTION}

In a highly competitive market, marketers often have to link brands to people, places, things, or other brands as a means of improving brand equity [1]. Collaboration can create new market opportunities in spaces that did not previously exist by combining resources and consumers from different sectors and sometimes different industries [2]. Even in alliance between brands, elements of brand fit perceived and product fit perceived also affect the preference of consumer attitudes toward brand alliance[3], and this joint marketing partnership between non-similar categories increases competitiveness and increases brand equity by sending strong signals to consumers for the combined benefits of the two brands[4]. Because of these advantages, companies are actively conducting brand collaboration marketing.

Since a few years ago, not only brand collaboration between similar categories but also between nonsimilar categories with broken boundaries have become a trend in market of the Republic of Korea,, which have become an effective marketing tool for brands as well as an essential strategy. Previously, the same industry, celebrities, artists, and characters were the main targets of collaboration, but the object and form of collaboration have gradually evolved amid rapidly changing trends and intensifying market competition. Collaboration, which was mainly conducted in the fashion industry, is now being conducted in various fields, including food, games, finance, automobiles, airline and hotels, and among them brand collaboration between very familiar brands to consumers or cooperation between completely different fields of products, which is brand collaboration between non-similar categories is gaining popularity. One of the reasons for the increased popularity is that it is an effective marketing tool that can stimulate the purchase needs of Millennials and Generation Z, the center of fashion and trends. They want a brand that gives them a unique feeling. In addition, they have a big influence on the consumer industry because they consume fun elements of products, share their experiences on social networks, and share not only their 
purchase power but also their consumption experiences quickly in a short period of time through SNS channels [5, 6]

Among collaboration products that are gaining popularity in all areas, why are unique and individualistic brand collaboration products between non-similar categories popular like this? And how does perceived novelty · perceived fit depending on the type of collaboration of product categories affect product attitude? This study sought to identify two paths (novelty and fit) of the impact of brand collaboration type on product attitude and the moderating effect of age that affects the path.

\section{Literature review and hypotheses}

\subsection{Collaboration}

In an uncertain, confused and rapidly changing environment, companies are motivated to cooperate with each other [7], and more and more brands are offering a single product or carrying out cooperative activity through interconnection [3]. This is because a strategic alliance reduces high development costs, reduces the risk depending on product introductions, and provides access to internal capabilities that you do not have [7]. A new type of organization is emerging with rapid changes in technology, scarce resources, and increased interdependence of organizations. Collaboration between organizations is a process of interacting through negotiations and as a process involving the interaction of shared norms and mutual interests in a relationship, it is a higher level of collective action than cooperation or coordination [8]. The dictionary definition of "Collaboration" refers to a situation in which two or more people work together to create or achieve the same thing, and in a business sense the act of creating or achieving something in cooperation with another person or organization [9]. Looking into the researchers' academic definitions, a well-defined relationship in which two or more organizations benefit each other to achieve common goals, and this relationship includes mutual authority and responsibility for success, sharing resources and rewards and promises for joint responsibility [10].

\subsection{Novelty}

The dictionary meaning of novelty is new and unusual characteristic, something interesting that has never been experienced before, new and unusual experiences and events. In other words, novelty is something new and interesting. [11, 12]. Looking at the researchers' definition, it can be explained by differences in perception of past experience and reality[13], and the study of consumer behavior suggests that the pursuit of novelty is a desire for new stimulation and experience and is related to the inclination to buy new products[14]. The novelty is studied in various fields, in the field of tourism, novelty is described as a concept contrasting with familiarity or boredom caused by repeated stimuli and it consists of thrill, change from daily life, relaxation of boredom, and dimension of surprise [15]. In addition, novelty is said to be the basic motivation to move for tourists to find new experiences [16]. In the study of psychology, novelty is the key to understanding a complex level of motivation in humans, and it is explained as an impulse to escape from monotony and boredom and move on to a new form of stimulation. And, active efforts to pursue new experiences and understand them are the basis of various activities [17]. Novelty in marketing research creates interest when new products are encountered, which means a positive emotional experience and interest is the consumer's motive for preferring novelty, improving consumer assessment and purchase intention [18]. Because recognition memory is better remembered for new or unusual items than non-novel items, it plays an important role in memory [19].

\subsection{Fit}

Regarding the expansion of the brand, 'perceived fit' is a subject that has been studied a lot and has still been studied continuously in various fields. In brand expansion, as for the original brand and the extended brand, the relationship between positive quality image for the original brand and brand expansion evaluation was strong only when there was a fit between the two product classes. Fit and Similarity between product categories have a positive effect on product attitudes [20]. The brand fit awareness and the product fit awareness have a significant impact on product attitudes even in brand alliances [7], and fit of product, fit of brand and new product brand fit have a positive impact on new cobranded products [21]. consumer risk perception is low and reliability and expected utility are increased when brand associations are continually consistent [22]. 


\subsubsection{Similarity between product categories}

In order to understand many new products, existing products and services in the market, consumers classify and interpret this information and use it categorically. These consumer categories can be defined as a set of consumer-related events, such as products, services, brands, or marketing [23]. Determining a brand association is often based on brand-wide similarities using attributes that represent product categories. Therefore, a link can be made by linking the brand, using a common attribute (i.e., a shared attribute) between brands [24]. In the existing brand expansion study, the concept of similarity between products is an important basis for determining the cognitive fit of the brand and its scalability, and the perceived fit of consumers for extended products is measured as a function of product similarity determination[25].

Putting the above together, the following hypotheses are established regarding perceived novelty · perceived fit and product attitude according to brand collaboration types.

Hypothesis 1: Novelty will be perceived more in Brand Collaboration between non-similar brand categories than similar ones.

Hypothesis 2: Fit will be perceived more in Brand Collaboration between similar categories than nonsimilar ones.

Hypothesis 3: Perceived Novelty will have a positive effect on Product Attitudes.

Hypothesis 4: Perceived Fit will have a positive effect on Product Attitudes.

\subsection{Millennials and generation $Z$}

For Millennials, which has been gaining attention worldwide, showing great influence in consumer behavior and Generation Z, the leading consumer group of the future, the U.S. research firm 'Pew Research Center' classified Millennials into generations born between 1981 and 1996 and Generation Z into generations born between 1997 and 2012 [26]. The Millennials in characteristics, also known as Generation Y, do not like stereotypes and want to be treated as a unique individual. Also, while the previous generation was responsive to marketing, the Millennials want to interact with the brand, coparticipate in the product and participate in the brand experience. They are a curious, open generation looking for a brand that give off a unique feeling [5,27]. The Millennials tends to appreciate the efforts in multicultural marketing, so many brands continue to make attempts to appeal to them through a message of cultural diversity [28]. American educator Marc Prensky named a generation familiar with digital devices 'Digital Natives.' They are generations who think and act differently from the past. They prefer images over text [29]. Generation Z in the next generation characteristics, shows loyalty to companies that aspire to Novelty and experience, have significant consumption power both online and offline, and offer personalized experience, limited edition products and unique products to realize the value of Generation Z, according to Criteo's 'Gen Z Report'. They cited 'UNIQUE' the most frequently used word to describe themselves and expressed their willingness to spend more for unique products that help define themselves $[6,30]$. The thing that Millennials and Generation $\mathrm{Z}$ have in common is that they are all attracted to something like new and unique products or brands $[5,6]$

Therefore, although the impact of perceived novelty on product attitude will not have a significant impact on those in their 30s or older, it is expected to be moderated by people in 10s and 20s (Millennials, Generation Z), and the following hypotheses are set up.

Hypothesis 5: The effect of Perceived Novelty on Product Attitude will be moderated by Age.

\section{Research model}


Based on the theoretical background and prior research we discussed earlier, we wanted to find out the differences in the degree to which novelty · fit is perceived respectively depending on brand collaboration types(similar category vs. non-similar category), and to check the impact of perceived novelty - fit on product attitudes respectively. Also, in anticipating that relation between perceived novelty and product attitude are moderated by age (10s $\sim 20$ s vs. 30 s or older), the research model was set up as shown in [Figure 1] below.

1

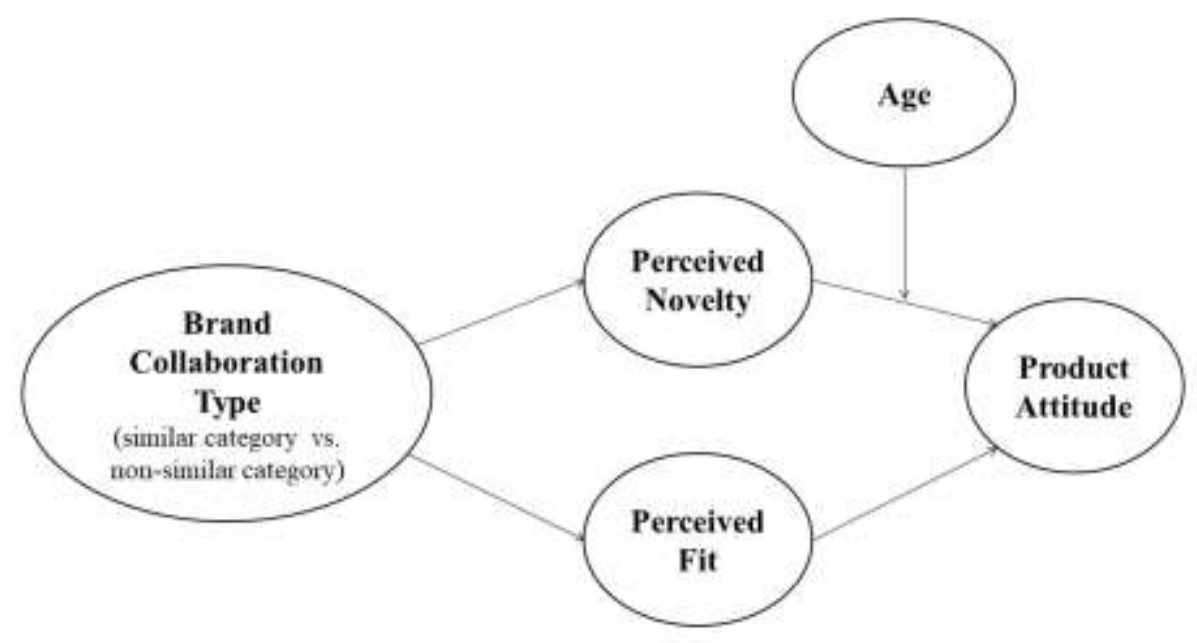

Figure

Research model

\section{Method}

4.1.

Pre-survey and develop stimulants

Prior to this experiment, the brands to be used in the comparative study of brand collaboration between similar categories and non-similar categories for the development of stimulants were selected through a preliminary survey.

In this research, we wanted to increase reliability with perception through brand experience by using real brands rather than virtual ones. About 25 surveys were collected online and offline, and based on these, 'FILA' and 'UNIQLO' were selected as collaborative brands between similar categories, 'FILA' and 'Oreo $\mathrm{O}^{\prime} \mathrm{z}$ ' of POST, a cereal brand were finally selected as collaborative brands between non-similar categories. Before the selected brand was used as a stimulant, the familiarity and preference between the two brands for each type of collaboration were compared to measure whether the brand selection was appropriate, and the result was confirmed that there was no difference between the two. In addition, the collaboration 
product line to be used for stimulants consists of stimulants, such as FILA $\rightarrow$ sneakers, UNIQLO $\rightarrow$ clothes and Oreo $\mathrm{O}^{\prime} \mathrm{z} \rightarrow$ serials, which can represent each selected brand.

\subsection{Experimental design}

Each of the two brands to be presented in the brand collaboration type (similar category vs. nonsimilar category) of stimulants was designed as follows, so that they can be tested at an equal location. The experimental groups consisted of 4 groups [brand collaboration type between similar category: brand A(FILA) $\times$ brand B(UNIQLO), adversely brand $\mathrm{B}(\mathrm{UNIQLO}) \times$ brand A(FILA) / brand collaboration type between non-similar category: brand A(FILA) $\times$ brand C(Oreo $\left.0^{\prime} z\right)$, adversely brand C(Oreo $\left.0^{\prime} z\right) \times$ brand A(FILA)] in brand collaboration type which is an independent variable, so a total of four types of questionnaires were produced. T-test tests were conducted to compare familiarity and preference between the two collaborative brands, and it is confirmed that both of all are found to have no difference between the two and be suitable for selecting stimulants. All measurement items applied to the questionnaire were partially modified and finally applied to the purpose of measurement of this study, based on those used in previous prior studies.

\subsection{Experimental procedure}

This study is about 'brand collaboration marketing' in the Korean market and surveyed Korean consumers. There is a total of four types of questionnaires. Questionnaires were produced and distributed and collected for about four weeks from October 22, 2018 to November 19, 2018. The questionnaires were written by the self-written method in which respondents took a look and filled out the questionnaire themselves, with a total of 268 questionnaires collected online and offline, and a total of 250 questionnaires were used in the final analysis, except for unfaithful or inappropriate responses(18). For the empirical analysis the data is analyzed by using the statistical program SPSS 22 and the sample characteristics of the survey respondents were examined through frequency analysis. In addition, through a factorial analysis to determine whether variables measuring the same concept are grouped into the same factors, how accurately the concept to be measured was measured was figured out. Internal consistency was verified by measuring Cronbach's Alpha coefficient through reliability analysis, and t-test and univariate analysis (ANOVA) and regression analysis were used for the analysis.

\subsection{Characteristic of a sample}

A total of 250 respondents were surveyed, and in terms of sample characteristics, the gender distribution was $48.4 \%$ and $51.6 \%$ for men and women, respectively and in age distribution, those in their 20 s were the most at $43.2 \%$ and $23.6 \%$ for 40 s and older, $18.4 \%$ for teenagers, and $14.8 \%$ for $30 \mathrm{~s}$ in order. This was used in the analysis of this study, divided into Millennials · Generation Z 10s and 20s(154 people_61.6\%) vs. 30s and older(96 people_38.4\%) and especially the research focused on the current main consumer base, so the proportion of survey respondents is higher in $10 \mathrm{~s}$ and $20 \mathrm{~s}$ than in $30 \mathrm{~s}$ and older. The distribution by academic background was $18 \%$ for under high school graduate, teenagers, $32.8 \%$ for college, $26.8 \%$ for college graduate, $14 \%$ for high school graduates, teenagers, $32.8 \%$ for university student, $26.8 \%$ for college graduates, $14 \%$ for graduates and graduate graduates, and the distribution by occupation was the largest with $51.2 \%$ of students.

\section{Hypothesis tests}

\subsection{Test of hypothesis 1,2}

T-test tests were conducted to compare the average of the two groups and determine the degree of perception of Perceived Novelty and Perceived Fit according to brand collaboration types.

Step 1: The analysis result by setting the brand collaboration type (similar category vs. non-similar categories) as an independent variable and the Perceived Novelty as a dependent variable is as shown in [Table1]. With $\mathrm{M}_{\text {similar category }}=4.42, \mathrm{M}_{\text {non-similar category }}=5.25, \mathrm{t}=-5.62, \mathrm{p}<0.05$, the Novelty is perceived higher for them between non-similar categories than for collaboration products between similar ones. thus, hypothesis 1 was supported.

Table1 Brand collaboration on type perceived novelty 


\begin{tabular}{|c|c|c|c|c|c|c|}
\hline $\begin{array}{l}\text { Independent Variable } \\
\text { (Brand Collaboration Type) }\end{array}$ & $\begin{array}{l}\text { Dependent } \\
\text { Variable }\end{array}$ & $M$ & $N$ & $S D$ & $t$ & $p$ \\
\hline Similar Category & \multirow{2}{*}{$\begin{array}{l}\text { Perceived } \\
\text { Novelty }\end{array}$} & 4.42 & 143 & 1.27 & \multirow{2}{*}{-5.62} & \multirow{2}{*}{.00} \\
\hline Non-Similar Category & & 5.25 & 107 & .98 & & \\
\hline
\end{tabular}

Step 2: In the test of hypothesis 2, t-test analysis was performed on brand collaboration types as independent variables and Perceived Fit as dependent variables, and the results are as shown in [Table2]. With $\mathrm{M}_{\text {similar category }}=3.95, \mathrm{M}_{\text {non-similar category }}=2.97, \mathrm{t}=5.76, \mathrm{p}<.0 .05, \mathrm{t}=5.76$ and $\mathrm{p}<0.05$, Fit was perceived higher for them between similar categories than for collaboration products between non-similar ones. Therefore, hypothesis 2 was supported.

Table2 Brand collaboration type on perceived fit

\begin{tabular}{|c|c|c|c|c|c|c|}
\hline $\begin{array}{l}\text { Independent Variable } \\
\text { (Brand Collaboration Type) }\end{array}$ & $\begin{array}{l}\text { Dependent } \\
\text { Variable }\end{array}$ & $M$ & $N$ & $S D$ & $t$ & $p$ \\
\hline Similar Category & \multirow{2}{*}{ Perceived Fit } & 3.95 & 143 & 1.31 & \multirow{2}{*}{5.76} & \multirow{2}{*}{.00} \\
\hline Non-Similar Category & & 2.97 & 107 & 1.35 & & \\
\hline
\end{tabular}

\subsection{Test of hypothesis 3,4}

Step 1: For the test of hypothesis 3 that perceived novelty would have positive effects on product attitudes, the perceived novelty was set as an independent variable and the product attitude as a dependent variable and the regression analysis was performed. In the case of product attitude, as shown in [Table 3] below, perceived novelty is shown to have a positive effect on product attitudes. So, hypothesis 3 was supported $(\mathrm{t}=14.30, \mathrm{p}<0.05)$.

Table3 Perceived novelty on product attitude

\begin{tabular}{llllll}
\hline Independent Variable & $\begin{array}{l}\text { Dependent } \\
\text { Variable }\end{array}$ & $\boldsymbol{S E}$ & $\boldsymbol{\beta}$ & $\boldsymbol{t}$ & $\boldsymbol{p}$ \\
\hline Perceived Novelty & Product Attitude & .05 & .67 & 14.30 & .00 \\
\hline
\end{tabular}

Step 2: In order to test hypothesis 4 that perceived fit would have a positive effect on the product attitude, the Perceived Fit was set as an independent variable and the product attitude as a dependent variable and the regression analysis was performed. As shown in [Table 4] below, for product attitudes, the Perceived Fit was shown to have a positive effect on product attitude. So, hypothesis 4 was supported $(\mathrm{t}=9.62, \mathrm{p}<0.05)$.

Table 4 Perceived fit on product attitude

\begin{tabular}{|c|c|c|c|c|c|}
\hline Independent Variable & $\begin{array}{l}\text { Dependent } \\
\text { Variable }\end{array}$ & $S E$ & $\boldsymbol{\beta}$ & $t$ & $p$ \\
\hline Perceived Fit & Product Attitude & .05 & .52 & 9.62 & .00 \\
\hline
\end{tabular}




\subsection{Test of hypothesis 5}

Step 1: univariate analysis was conducted to test the moderating effect of age $110 \mathrm{~s} \sim 20 \mathrm{~s}$ vs. $30 \mathrm{~s}$ or older) in hypothesis 5 . Test of hypothesis 5 the results of the analysis by selecting the Perceived Novelty as an independent variable, the age as a moderator variable, and the product attitude as a dependent variable are as follows [Table 5] and [Table 6]. The average age of product attitudes was higher for those in $10 \mathrm{~s}$ and 20 s than in 30s and older, and significance probabilities corresponding to perceived novelty . age - perceived novelty and age interactions(Perceived Novelty* Age) are $\mathrm{p}<0.05$, and the Age acts as the moderator variable in the relationship between Perceived Novelty and Product Attitudes. Therefore, hypothesis 5 was supported.

Table 5 Descriptive statistics

\begin{tabular}{llccc}
\hline Age & $\begin{array}{l}\text { Dependent } \\
\text { Variable }\end{array}$ & $\boldsymbol{N}$ & $\boldsymbol{M}$ & $\boldsymbol{S D}$ \\
\hline $\begin{array}{l}\text { under } 30 \\
(10 \mathrm{~s} \sim 20 \mathrm{~s})\end{array}$ & $\begin{array}{c}154 \\
\text { Product } \\
\text { Attitude }\end{array}$ & 96 & 4.45 & 1.40 \\
\cline { 3 - 5 } & & 4.11 & 1.20 \\
\hline
\end{tabular}

Table 6 Moderating effect of age

\begin{tabular}{|c|c|c|c|c|c|c|}
\hline $\begin{array}{l}\text { Independent } \\
\text { Variable }\end{array}$ & $\begin{array}{l}\text { Dependent } \\
\text { Variable }\end{array}$ & Sum of Squares & $D F$ & $\begin{array}{l}\text { Mean } \\
\text { Square }\end{array}$ & $\boldsymbol{F}$ & $p$ \\
\hline $\begin{array}{l}\text { Perceived } \\
\text { Novelty (A) }\end{array}$ & & 183.75 & 1 & 183.75 & 188.79 & .000 \\
\hline Age (B) & Product Attitude & 4.41 & 1 & 4.41 & 4.53 & .034 \\
\hline$A^{*} B$ & & 5.60 & 1 & 5.60 & 5.75 & .017 \\
\hline
\end{tabular}

Step 2: t-test was conducted to compare the average Age between Perceived Novelty [high Novelty, low Novelty] and Product Attitudes. The results of the analysis are the same as [Table 7] and [ Figure 2], and in the case of high Perceived Novelty the effect on product attitudes is $m=4.77$ in 30 s or older, and $\mathrm{m}=5.24$ in $10 \mathrm{~s}$ and $20 \mathrm{~s}$, so it is found that Perceived Novelty has a greater positive effect on Product Attitudes when they are $10 \mathrm{~s}$ and $20 \mathrm{~s}$ than 30 s or older. $(\mathrm{t}=1.82, \mathrm{p}<0.1)$

Table 7 Moderating effect of age

\begin{tabular}{|c|c|c|c|c|c|c|c|}
\hline $\begin{array}{l}\text { Perceived } \\
\text { Novelty }\end{array}$ & Age & $\begin{array}{l}\text { Dependent } \\
\text { Variable }\end{array}$ & $M$ & $N$ & $S D$ & $t$ & $p$ \\
\hline \multirow{2}{*}{ High } & $10 \mathrm{~s} \sim 20 \mathrm{~s}$ & \multirow{4}{*}{ Product Attitude } & 5.24 & 64 & 1.25 & \multirow{2}{*}{1.82} & \multirow{2}{*}{0.07} \\
\hline & 30 s or older & & 4.77 & 35 & 1.17 & & \\
\hline \multirow{2}{*}{ Low } & $10 s \sim 20 s$ & & 3.20 & 42 & 1.16 & \multirow{2}{*}{-0.36} & \multirow{2}{*}{0.72} \\
\hline & 30 s or older & & 3.28 & 40 & 0.97 & & \\
\hline
\end{tabular}




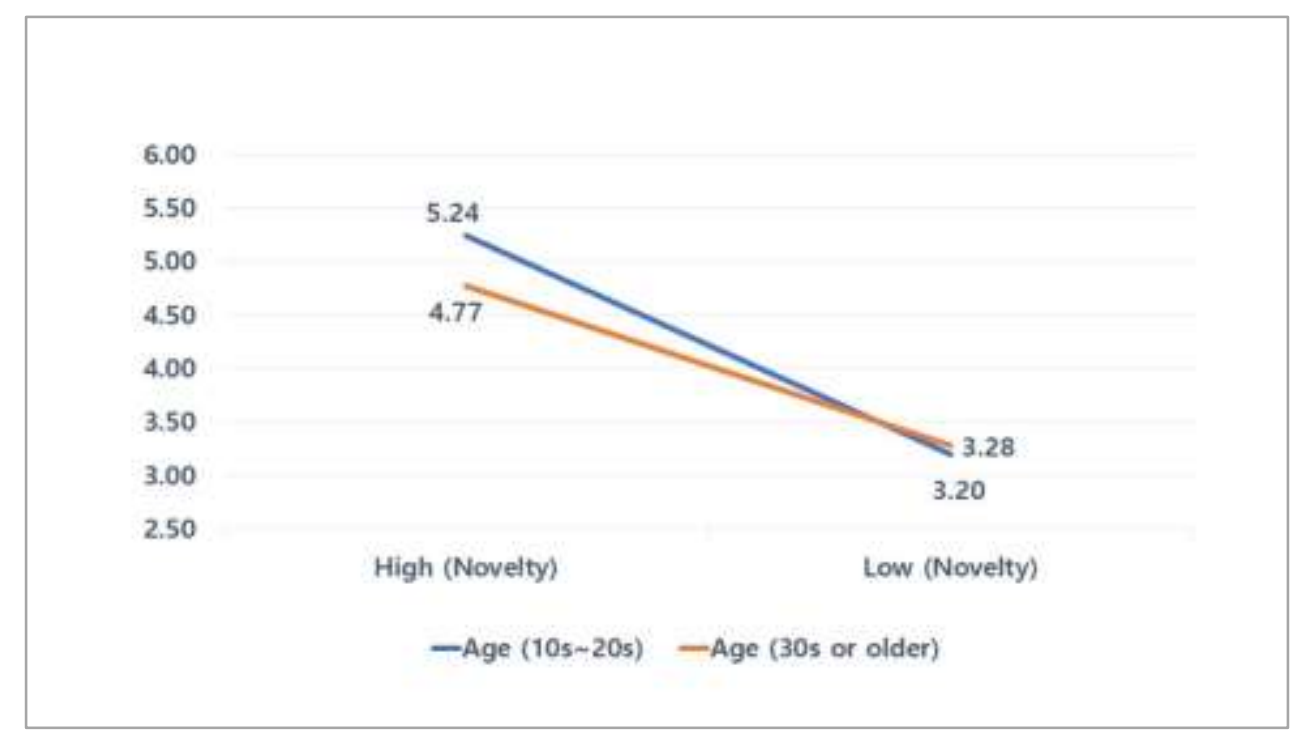

Figure 2 Moderating effect of age

\section{Conclusion, discussion and implications}

\subsection{Conclusion}

By this study I wanted to check the effect of perceived Novelty · perceived Fit on product attitude according to brand collaboration type and whether the relationship is moderated by age, and the results are as follows. 1) Perceived Novelty of brand collaboration type was perceived higher in collaboration between non-similar categories than in collaboration between similar ones, and perceived Fit was perceived higher in collaboration between similar categories than collaboration between non-similar ones. 2) Perceived Novelty $\cdot$ perceived Fit had a positive effect on product attitude respectively. 3) The relationship between perceived Novelty and Product Attitude was moderated by Age (10s 20s vs. 30s or older). In other words, the effect of perceived Novelty on Product Attitudes for non-similar categories collaboration was found to be greater in the 10 s and 20 s than in the 30 s and older age groups. Brand collaboration is a viable strategy that extends the brand's value from functional level to emotional and self-expressed level [31], and has a positive effect on product attitudes because it conforms to the characteristics of the new generation, Millennials and Generation Z. In other words, the new generation is attracted to new things, like products or brands that can be expressed as unique individuals and wants to buy these products. Also, results related to perceived fit confirmed once again that perceived fit according to brand collaboration between similar categories had a positive effect on product attitudes, just like the existing prior study that fit and similarity between product categories have a positive effect on product attitudes [20].

\subsection{Discussion and implications}

Based on the analysis results, this study suggests that: the greatest implication of the study is that the relationship between the variable called "novelty" and various variables, which has not been addressed much in the field of collaboration, has been established. The research result that the characteristics and consumption trends of Millennials and Generation $\mathrm{Z}$ who prefer unique, original and creative products are reflected and they feel different and interesting about products by highly perceived Novelty in collaboration between non-similar categories and consequently have a positive attitude toward products will be practically helpful in the future brand marketing field. In addition, when conducting collaborative marketing targeting consumers in 30 s or older, it may be more effective to implement collaborative marketing that reflects it, rather than blindly following the current trend of brand collaboration between non-similar categories, as shown in the study, since they have a more positive attitude toward brand collaboration products between similar categories. Since the questionnaire of this study was collected 
through the responses of consumers in Republic of Korea, it is thought that additional national studies would help with overseas marketing strategies. This is because we will be able to carry out successful marketing strategies when collaborating with foreign brands or when domestic brands make inroads into foreign markets, if we can identify the consumption characteristics of Millennials and Generation $\mathrm{Z}$ by country. It is hoped that more diverse collaborative marketing and research related to MZ generation (Millennials \& generation Z) will continue in the future.

\section{References}

[1] Keller KL. Brand synthesis: The multidimensionality of brand knowledge. Journal of consumer research. 2003 Mar 1;29(4):595-600.

[2] Calagione S. Off-Centered Leadership: The Dogfish Head Guide to Motivation, Collaboration and Smart Growth. John Wiley \& Sons; 2016 Feb 23.

[3] Simonin BL, Ruth JA. Is a company known by the company it keeps? Assessing the spillover effects of brand alliances on consumer brand attitudes. Journal of marketing research. 1998 Feb;35(1):30-42.

[4] Ahn S, Kim H, Forney JA. Co-marketing alliances between heterogeneous industries: Examining perceived match-up effects in product, brand and alliance levels. Journal of Retailing and Consumer Services. 2009 Nov 1;16(6):477-85.

[5] NPD Group. Sneakernomics: Marketing with Millennials, Part 2 [Internet]. 2017 [cited 2020 Aug 12]. Available from: https://www.npd.com/wps/portal/npd/us/blog/2017/ sneakernomics-marketing-with-millennials-part-2/.

[6] NPD Group. Sneakernomics: Here Comes Gen Z, Part 2 [Internet]. 2017 [cited 2020 Aug 12]. Available from: https://www.npd.com/wps/portal/npd/us/blog/2017/sneakernomicshere-comes-gen-z-part-2/.

[7] Kotabe M, Scott Swan K. The role of strategic alliances in high-technology new product development. Strategic management journal. 1995;16(8):621-36.

[8] Thomson AM, Perry JL. Collaboration processes: Inside the black box. Public administration review. 2006 Dec;66:20-32.

[9] Cambridge Dictionary. Collaboration. [Internet]. [cited 2020 Aug 15]. Available from https://dictionary.cambridge.org/dictionary/english/collaborate?q=COLLABORATION.

[10] Mattessich PW, Monsey BR. Collaboration: what makes it work. A review of research literature on factors influencing successful collaboration. Amherst H. Wilder Foundation, 919Lafond, St. Paul, MN 55104.; 1992.

[11] Cambridge Dictionary. Novelty [Internet]. [cited 2020 Aug 17]. Available from: https:// dictionary.cambridge.org/dictionary/english/novelty?q=NOVELTY.

[12] Collins. Novelty [Internet]. [cited 2020 Aug 17]. Available from: https://www. collinsdictionary.com/dictionary/english/novelty.

[13] Pearson PH. Relationships between global and specified measures of novelty seeking. Journal of Consulting and Clinical Psychology. 1970 Apr;34(2):199.

[14] Hirschman EC. Innovativeness, novelty seeking, and consumer creativity. Journal of consumer research. 1980 Dec 1;7(3):283-95.

[15] Lee TH, Crompton J. Measuring novelty seeking in tourism. Annals of tourism research. 1992 Jan 1;19(4):732-51.

[16] Duman T, Mattila AS. The role of affective factors on perceived cruise vacation value. Tourism management. 2005 Jun 1;26(3):311-23.

[17] Berlyne DE. Novelty and curiosity as determinants of exploratory behaviour. British Journal of Psychology. 1950 Sep 1;41(1):68.

[18] Sung B, Vanman E, Hartley N. Interest, but not liking, drives consumer preference toward novelty. Australasian Marketing Journal (AMJ). 2019 Nov 1;27(4):242-8.

[19] Kishiyama MM, Yonelinas AP. Stimulus novelty effects on recognition memory: Behavioral properties and neuroanatomical substrates. Distinctiveness and memory. 2006 Apr6:381-404.

[20] Aaker DA, Keller KL. Consumer evaluations of brand extensions. Journal of marketing. 1990 Jan;54(1):27-41.

[21] Bouten LM, Snelders D, Hultink EJ. The impact of fit measures on the consumer evaluation of new co-branded products. Journal of Product Innovation Management. 2011 Jul;28(4):455-69.

[22] Erdem T, Swait J. Brand equity as a signaling. Journal of consumer Psychology. 2001; 
7(2):131-57.

[23] Loken B, Barsalou LW, Joiner C. Categorization theory and research in consumer psychology: Category representation and category-based inference.

[24] Bettman JR, Sujan M. Effects of framing on evaluation of comparable and noncomparable alternatives by expert and novice consumers. Journal of Consumer Research. 1987 Sep 1;14(2):141-54.

[25] Park CW, Milberg S, Lawson R. Evaluation of brand extensions: The role of product feature similarity and brand concept consistency. Journal of consumer research. 1991 Sep 1;18(2):185-93.

[26] Pew Research center. Defining generations: Where Millennials end and Generation $\mathrm{Z}$ begins [Internet]. 2019 [cited 2020 Aug 20]. Available from: https://www. pewresearch. org/fact-tank/2019/01/17/where-millennials-end-and-generation-z-begins/.

[27] Fromm J, Garton C. Marketing to millennials: Reach the largest and most influential generation of consumers ever. Amacom; 2013 Jul 10.

[28] Licsandru TC, Cui CC. Ethnic marketing to the global millennial consumers: Challenges and opportunities. Journal of Business Research. 2019 Oct 1;103:261-74.

[29] Prensky M. Digital natives, digital immigrants. On the horizon. 2001 Nov;9(5).

[30] Retail Leader. Here's how to win Gen Z shoppers [Internet]. 2018 [cited 2020 Aug 20]. Available from: https://retailleader.com/heres-how-win-gen-z-shoppers.

[31] Uggla H, Åsberg P. The Benefits and Risks of Strategic Brand Collaboration. IUP Journal of Brand Management. 2010 Sep 1. 